\title{
Research on the Chaos, Causes and Countermeasures of Information Dissemination in WeChat Moments
}

\author{
Pengfei $\mathrm{Xu}^{1} \mathrm{Zeju} \mathrm{Li}{ }^{2, *}$
}

\author{
${ }^{1}$ School of Communication, Yangtze Normal University, Chongqing, China \\ ${ }^{2}$ Chongqing Medical University, Chongqing, China \\ *Corresponding author. Email: 603302885@qq.com
}

\begin{abstract}
Moments is one of the functional units of WeChat, which has many functions such as sharing information, forwarding information, spreading information, commenting information and interactive communication, etc. The privacy nature of WeChat Moments and the lag of audit cause netizens' communication chaos such as false information, vulgarization of content, WeChat business spamming and disruption of fair competition, etc. when they disseminate information in WeChat Moments. The research finds that the main reasons for the chaos of information communication in the WeChat Moments are the communicator's low media literacy and the audience's weak consciousness of independent critical thinking and the imperfect management system, etc. Therefore, it is necessary to improve the media literacy of the public, strengthen the self-discipline consciousness of individuals, and improve the management system.
\end{abstract}

Keywords: information dissemination, media literacy, WeChat, Moments

\section{INTRODUCTION}

The Moments is one of the most active, popular and core functions in WeChat foundation module. It is a bridge and visual platform for interaction and communication between WeChat friends. [1] WeChat affects many aspects of Chinese people's life and forms the WeChat life of Chinese people. [2] There have been studies made from the perspective of the information transmission pattern in WeChat Moments [3], the privacy settings function and privacy protection means of WeChat Moments [4], the immersive advertising in WeChat Moments [5], the limited publicity of WeChat Moments[6], the first person effect of information dissemination in WeChat Moments [7], the strategic patterns and influencing factors of self-presentation in WeChat Moments [8], user anxiety [9], burnout emotion [10], media literacy [11] [12], motivation analysis for "thumb-up" behavior in WeChat Moments [13], and the possibility that the publicity of private life and privatization of public life in WeChat Moments may lead to more social division and less consensus [2], etc., but there have been few studies related to information communication chaos in WeChat Moments. The main purpose of this topic research is to analyze various kinds of communication chaos in WeChat Moments and to put forward some opinions to address the chaos.

\section{THE INFORMATION COMMUNICATION CHAOS OF WECHAT MOMENTS}

The information communication chaos is a chaotic phenomenon of information that is vulgar or redundant or out of nothing, damaging the market competition environment, which plays a negative role in public opinion.

\section{A. Disseminating false information}

Network false information refers to information transmitted through the Internet media that is not based on objective facts, or is made out of nothing, or exaggerates things, or contains disguised replacement of information [3]. WeChat Moments is a virtual society in which everyone can publish information and it is hidden, making netizens become network "reporters". The continuous expansion of this ubiquitous "reporters" group is influenced by the differences of Internet users' gender, education level, nationality, occupation, region, values and other factors, which makes each "reporter" release information differently in essence. Without the professional cultural knowledge possessed by real reporters, it is inevitable for them to have subjective assumptions, fabrications and exaggerations when releasing information. Once the contents they released arouse the attention of netizens, they will be widely reproduced and become a controversial topic for a while. For example, the fake news of the "Shanghai Girl Escaping from an Village of Jiangxi" event attracted wide attention after the post of 
the netizen "想说又说不出口 (pronouncing xiang shuo you shuo chu kou, literally meaning wanting to say but just can't). Netizens reposted it one after another, and all the major portals and public accounts reposted it one after another, which aroused a heated discussion at that time. For a while, the gap between urban and rural areas, regional discrimination and other issues were on the cusp of public opinion. This kind of serious fake news was forwarded by major portal websites without strict investigation, which undoubtedly expanded the spread scope, caused bad social influence, and also put a question mark on the trust of major portal websites.

In recent years, the large number, fast speed and wide spread of fake news have been constantly influencing public opinion. While the Internet gives full discourse power to the Internet users, the excessively free virtual environment of the Internet also has much potential harm, which reduces the credibility of the news media, thus endangers the survival of the news media and causes mental damage to the Internet users.

\section{B. Disseminating vulgar information}

The definition of Internet vulgarization also focuses on pornography, privacy, violence, spoof and other keywords. However, these contents exist explicitly or implicitly in text, pictures, videos, blogs, online games, search engines, network literature and in other forms, which spread widely, replicate instantly, crossinfluence and penetrate deeply [4]. Internet vulgarization is nearly ubiquitous. The vulgarity also permeates WeChat Moments and the seemingly thought-making words and funny pictures are all well aware of vulgarization. People have grown to be more and more open-minded in that they have get used to what they saw as intolerable. The once negligible contents have grown to unstoppable trend and various forms of vulgarization alternate in our lives. Everyone who uses the Internet has inadvertently become the producer and user of vulgar culture. For example, some people share fortune-telling link on the Internet, etc., out of reasons ranging from the boredom, curiosity and fun, etc. Such behavior inadvertently discloses personal privacy and spreads vulgar culture. The "Violent Customer-chasing Incident of United Airlines" attracted extensive attention from netizens. Suddenly, the discussion about United Airlines exploded, and netizens made some spoof and ironic pictures to ridicule United Airlines. For example, some people posted "Attention, please! Dear gests of the United Airlines, please welcome your new attendant holding a 32-inch baseball bat Lucille from "The Walking Dead", or "If we fail the competition with our rival, we will beat our guests" [5].

\section{WeChat business spamming}

The term WeChat business came into being mainly after the rise of WeChat. In WeChat Moments, there is a "strong connection" between netizens and their friends. This "strong connection" relationship is mainly based on mobile phone contacts and QQ friends, and the offline relationship expanding to the online one, which enhances the relationship between netizens. The appearance of WeChat business affects this relationship in different ways. WeChat business, in a colloquial sense, sells all kinds of goods in the circle of friends through the "strong connection" between friends, so as to achieve the purpose of profit. On the one hand, WeChat business provides the seller with a way to make money, in that the moderate release of information not only makes them money but also strengthens their relationship with friends in the circle. Yet spamming will get just the opposite. Flooding with redundant and meaningless information affects friends' browsing other information and will make friends in the circle become bored and resistant over time.

Such information spamming in the Moments occupies the major part of many people. With a close look at the shares of such friends, it can be seen that what they keep posting are no more than promoting products. From packaging to sending out, they give at least 7 to 8 posts a day, and the number sometimes reaches a dozen. WeChat friends circle has become a shopping platform. Since the sellers are individuals without corresponding business license, the product does not have the security guarantee, the purchase of the product does not have the corresponding invoice receipt, it is very difficult for consumers to protect their rights. Despite being built on the "strong connection" of being WeChat friends, there is also the phenomenon that the seller ignores buyers appeal, refuses goods exchange or return. As a result, consumers' hard-earned money will be gone.

\section{Disrupting fair competition}

The important display of disturbing fair competition is WeChat's interactive function of thumbing up. When there are new posts from friends in Moments, users can give thumbs up through clicking the "like" below. For a while, seeking "likes" was prevalent, and to this day it still happens. Seeking "likes" is mainly some activities held by companies in order to increase awareness and promote sales growth. By posting the "likes-seeking" information in the circle of friends, netizens can collect the number of "likes" required by the activity party. Those who achieve the "likes request" will get certain returns. In a period of time, "likes" seekers are everywhere, posting like "My kid has joined the cutest baby campaign. Help out with the likes, please", "I want to buy this dress, please help me by giving me a like so that I can save a lot of money" and "Please give me likes so that I can get this product for free", etc. Such stuff keeps requesting people to subscribe public accounts and add friends and fill the "likes-seeking" information with the Moments. Businesses should be in the fair competition to improve their own economic 
benefits and visibility. This kind of marketing method, which relies on making people to seek "likes" to gain popularity, misleads consumers to conduct objective shopping, which is a kind of deception for consumers and also disrupts the economic order of fair competition in the market.

\section{THE CHARACTERISTICS AND HARM OF THE INFORMATION SPREADING CHAOS IN WECHAT MOMENTS}

\section{A. The characteristics of information spreading chaos in WeChat Moments}

1) Virtuality: WeChat Moments is an invisible and intangible virtual world where everyone can post messages at will. Although WeChat users were authenticated with their real names in the "Regulations" issued by the Cyberspace Administration of China in 2014, WeChat which features privacy and stealthiness makes the information posted by Internet users limited to friends. In a sense, the inclusiveness of friends frees users from the worry about the consequences of posting information. As a result, the generation of false, vulgar, spamming, thumb up and other communication chaos has become extremely normal, the virtuality and quickness of network communication promote the everexpanding disseminating scope of bad information.

2) Mass information: The low threshold of WeChat makes it available to the elderly from 70 to 80 , as well as to children from a few years old. The user group is constantly expanding, regardless of class. It is used by advanced intellectuals and groups with a low level of education. Therefore, information released can either be elegant or vulgar, and the Internet, with its imperfect management system, is powerless in the face of all kinds of communication chaos, which leads to more bad information. New media, which are decentralized new media with which everyone is a reporter, has resulted in a huge amount of information. Moreover, due to the lack of systematic and comprehensive education of cultural knowledge to all, there is a large amount of mixed information, and it is difficult to distinguish the true from the false.

3) Universality: Universality has two main meanings here. One refers to the wide content. There is much more communication chaos in the Moments than false information, vulgarization, WeChat business spamming and "likes seeking". More communication chaos that hasn't been studied can be found from actual life such as sensational headline, fraud information and malicious link. The other refers to the wide spread. Due to the high speed and free time of network communication, the spread scope of the communication chaos is constantly expanding, and all kinds of bad information, such as viral spread, permeates into the complex network, which increases the difficulty of governance.

\section{B. The harm of information spreading chaos in We Chat Moments}

1) Harming the interests of communicators: Communication chaos are respectively false information, vulgarization and WeChat business spamming, "likes-seeking". The former is contents composed by the news media independently and by individuals, which leads to public opinion and is forwarded by various news media. For communicators, the appearance of communication chaos violates the characteristics of authenticity of news, reduces the credibility of news media, affects the guiding role of public opinion of news media, and then endangers the existence of news media. The latter refers to the spamming in Moments to seek likes, resulting in information redundancy, depriving WeChat Moments of its original "entertainment" function, leading to reduced customers and "loss" of some friends, affecting their own interests.

2) Harming the growth of teenagers: The emergence of such communication chaos as "inferior" information, which harms the growth of teenagers, is more misleading for the immature group of primary and secondary school students and the adult group with a low level of education. Especially for primary and secondary school students, who are the future of the nation, their world outlook, outlook on life, values are not mature, and thus are susceptible to other opinions around and tend to follow suit. With strong curiosity and strong imitation ability, they are in the stage of accepting the level of cultural knowledge, and their rational cognition cannot catch up with their perceptual cognition, so they are easily affected by the spread of communication chaos, have their world outlook, outlook on life and values distorted, which affects their growth. Various vulgar, parodic, violent, pornographic text, video led them astray, which has become a cancer of the healthy growth of new generation.

3) Consumer fraud: There are a large number of WeChat businesses and easy likes, whose promoted products are virtual to the buyers. Sellers will post information about products on Moments, but in order to sell better, the information they post is often carefully selected or made by themselves to lure consumers to buy with just pictures instead of real objects. The buyer is deceived when the product is not in conformity with the seller's description. At the same time, this kind of network marketing destroys the market economic order 
of fair competition. In order to strengthen the influence of their brands, major businesses use WeChat business and WeChat likes to promote the sales of products, which does not conform to the fair and just competition order.

\section{THE REASON OF INFORMATION COMMUNICATION CHAOS IN WECHAT MOMENTS}

\section{A. Communicators have low media literacy}

As far as disseminators are concerned, the media literacy of netizens determines the "quality" of information when it is released. Media literacy refers to people's ability to choose, understand, question, evaluate, create, produce and respond critically to media information [6]. From obtaining information to releasing information, netizen's media literacy plays an important role in this process. For Internet users with high cultural knowledge, they can well distinguish what information is beneficial. For those that have been exposed to ideological and political education, Internet use education and other cultural knowledge, they can distinguish the good from the bad in normal news events. However, for the public opinion news which cause a large social response, it is easy for netizens to be affected by factors not related to the event itself, such as mood, ethnic identity, occupation, region, etc., netizens will choose one side selectively according to their own conditions, instead of making the choice out of a simple rational choice.

For example, the once famous "Shanghai Girl Escaping from a Village of Jiangxi" incident two years ago was found to be false from beginning to end after investigation. The poster "想说又说不出口" was a married woman and was not from Shanghai, who had an argument with her husband before the Spring Festival that year, not feeling like going back to her husbands' hometown and vented one's anger through the post. And the replier "风的世界伊不懂 (pronouncing feng de shi jie yi bu dong, literally meaning you won't understand the world of the wind)", was not even an acquaintance of the poster. The news showed that netizens lacked consideration when releasing information and did not assess its social impact. However, authoritative public accounts of news media dis not treat news with a professional and skeptical attitude before forwarding it, which expanded the spread scope of fake news and increased its influence.

\section{B. The audience has a weak sense of independent reasoning}

From the perspective of the recipient, in the complex virtual network environment, reading becomes fragmented in a fast-food style, and people become fickle. In the face of information, they lack independent thinking and accept ready-made theories and opinions, making critical thinking difficult to sustain. Critical thinking is a kind of insight, discrimination and judgment, is a deep understanding of the problem, comprehensive analysis and rational judgment, is the way and attitude to know things. It is also a process of recognizing what to affirm and what to deny or the process of thinking in the face of new ideas and measures [7]. The spread of communication chaos is largely due to the fact that netizens do not have the ability to think independently, distinguish right from wrong, and have no judgment and they believe what they think is right and are limited to the surface of things. They take for granted the ready-made theories and ideas brought to them by the communicator, and do not spend time and energy thinking about whether those theories and ideas are correct or not. They do not want to think, because they are content with the status quo and are lazy, and they are unable to analyze mentally, including the reserve of knowledge, practical experience. Third, the fickleness of the public

From the perspective of psychology, following suit is a universal psychological phenomenon owned by individuals. Few people can maintain their independence and avoid following the crowd in the face of common social phenomena. The spread of spreading chaos is partly due to the psychology of following the crowd. In Moments, netizens are making money on WeChat. They don't want to lag behind others, and they are afraid of being ignored and despised, so as to avoid being isolated. In the face of all kinds of public opinion information, it is easy to be influenced by the environment of social "majority" opinion, which tends to incur the phenomenon of "The Spiral of Silence". The theory of "The Spiral of Silence" mainly means that individuals should first observe the surrounding opinion environment when expressing their own views. When they find that they belong to the "majority" or "dominant" opinion, they tend to express their views positively and boldly. When they find themselves in a "minority" or "inferior" opinion, they turn to "keep silent" or chiming in with others. The "silence" of one side creates an increase in the opinion of the other side, which in turn forces more and more dissenters to turn to "silence", thus creating a "spiral in which one side becomes more and more vocal while the other becomes more and more silent" [8].

\section{The management system is not sound enough}

From the perspective of the management system, in the current management system, the government only stops content such as anti-unity, obscenity, pornography, violence and so on, but does not control the false, vulgar, spamming, "likes-seeking" and other communication chaos mentioned in this article. But there are no governance measures for the information such as communication chaos, which unavoidably 
contributes to the emergence and spread of chaos. In terms of management system, the management of information should not only manage big problems, but also start from small aspects. As quantitative changes cause qualitative changes, the management of communication chaos should also not be ignored.

\section{GOVERNANCE COUNTERMEASURES OF INFORMATION COMMUNICATION CHAOS IN WeChAT MOMENTS}

\section{A. Strengthening media literacy}

For the major professional news media, they should adhere to the Ideological line of Marxism, carry forward the work style of in-depth practical investigation and research, go deep into the grassroots, go deep into the masses, and avoid the "Kelok" practice ( referring to the deed of blabbing without having infield investigation) [9], strengthen their own professional quality, promote professional ethics, and review the theory and thought, to refresh themselves with the professional quality and responsibility of journalists and keep a cool head and avoid onesidedness. It is necessary for them to adhere to the principle of authenticity, and lead the people to establish a correct world outlook, outlook on life, values, better understanding of the world, promote social development.

The government and schools should strengthen media literacy education for students, especially for primary and middle school students. Primary and middle school students are in the stage of passive acceptance of knowledge and have no initiative to improve their own cultural literacy. Therefore, schools and governments, as educators, should take the initiative to assume this responsibility. In the face of new media technology, schools and governments should not only let them learn how to use new media, but also let them know how to use new media properly. It is important to strengthen ideological and political education, offer courses for them to improve their Internet media literacy according to the requirements of the times, so as to continuously enhance their independent thinking and self-discrimination ability. In this way, students can correctly treat the overwhelming mass of information and not be involved in bad information. At the same time, adults with low education level should be publicized for their laws and regulations, especially the newly promulgated Internet laws and regulations. Network media literacy publicity activities and knowledge question-and-answer activities should be conducted in communities and streets; and internal network knowledge education training should be conducted in some factories and companies to enhance the network culture education for staff.

\section{B. Individuals should hold the pass themselves}

As an independent individual, one should constantly improve their media literacy, improve their sense of holding the pass, and be able to make judgments when faced with information. At the same time, one should have the ability to question information, face various information with critical thinking, and think more, ask more and check more, instead of following the crowd At the same time, one should increase the amount of reading by reading some high-quality books to increase the reserve of knowledge and broaden the horizons.

\section{Improving the management system}

The government should promulgate relevant and feasible online laws and regulations to clearly define each content and procedure, and at the same time strengthen the openness and transparency of information to convey real information. Legally binding force and shock power realized by top-down government network management can greatly improve the online environment. For example, on August 7, 2014, Cyberspace Administration of China issued the interim provisions on the development and management of public information services of instant messaging tools [10], which standardizes and improves the institutional construction of the emerging Internet industry, and especially puts forward new requirements and measures on the management and use of WeChat.

\section{CONCLUSION}

To sum up, the communication chaos exists in WeChat circle of friends and is affected by many factors. This study discusses from the aspects of the communicator, the media, the government, etc., to make people realize that the occurrence of communication chaos is closely related to and has an inextricable relationship with everyone. It also tells people that only through the common efforts and cooperation can the current communication chaos in WeChat Moments be changed.

There are still some unresolved issues in addition to the ones mentioned in the research. To comprehensively study the communication chaos, a lot of time and energy are needed. In the following research, the research method can be extended to survey research and case analysis, and the communication content of many netizens' WeChat Moments can be consulted to subdivide the communication chaos. However, researches should look at problems from the perspective of primary and secondary school students more. Although primary and secondary school students are not the main group of users, the people using WeChat Moments have shifted to primary and secondary school students, which is very tempting for primary and secondary school students and requires extra attention. 
Everything exists in the unity of opposites. So it is necessary to treat this universal social phenomenon dialectically. To solve the problem of communication chaos, people from all walks of life need to work together, as the effect of the strength of just one side is not obvious. Only when all sides have the determination to change and the courage to do, can the chaos of communication and many other problems be addressed. Since primary and secondary school students are the hope and future of the nation, attention should especially be paid to the media literacy education for them. In general, to reduce the communication chaos, it is necessary stop it from the source, rather than simply reflect on and appeal after the event. However, there is still a long way to go to address the root cause of the problem, which requires the joint efforts of all parties.

\section{References}

[1] Cai Hongsheng, Hu Zhongyue. WeChat Moments of University People - from the Perspective of University Culture [J]. University Education Science. 2018 (5). (in Chinese)

[2] Jin xin. On WeChat Life [J]. Lanzhou Journal. 2018 (11). (in Chinese)

[3] Zeng Linhao, Zeng Zhenhua. Scene Fusion and Identity Confusion: the Use of WeChat Moments Under Media Context Theory [J]. Editors Monthly. 2019 (1). (in Chinese)

[4] Liu Qian. Research on Motivation of Privacy Management in WeChat Moments of Young Uses [J]. Contemporary Communications. 2019 (4). (in Chinese)

[5] Ma Mengjiao. Analysis and Thinking of Immersive Advertisement in WeChat Moments [J]. Youth Journalist. 2019 (5). (in Chinese)

[6] Ou jian. Limited Publicity of WeChat Moments — Based on Structure, Representation and Interaction [J]. Press Circles. 2019 (8). (in Chinese)

[7] Yu Mengyue. Study on the Propagation Effect of the First Person in WeChat Moments [J]. Media. 2019 (5). (in Chinese)

[8] Li Yungeng, Zhu Huanya. The Motivation of Sharing Moments with Friends: a Study on WeChat Self-presentation Strategies and Influencing Factors of College Students from the Perspective of Social Psychology [J]. Journalists. 2019 (5). (in Chinese)

[9] Wang Yaqian. A Study on the Unsustainable Use of Strong Relationship Social Media from the Perspective of Anxiety - a Case Study of WeChat Moments [J]. Press Circles. 2019 (10). (in Chinese)

[10] Qin Yanhua, Wang Yuanxin. Media Literacy Analysis of Social Media Users - Starting from the Phenomenon of "Audience Isolation" in WeChat Moments [J]. Chinese Editorials. 2019 (10). (in Chinese)

[11] Xiong Hui, Guo Qian. Research on Influencing Factors of Dropout Behavior in WeChat Moments [J]. Press Circles. 2019 (10). (in Chinese)

[12] Niu Jing, Chang Mingzhi. Research on Social Interaction Stressors and Intention of Unsustainable Use in Social Media [J]. Journalism \& Communication Review. 2018 (6). (in Chinese)

[13] Liu Lei, Zhang Huimin, Wang Xihao. Weak Connection and Strong Relationship: Analysis on the Social Motivation and Maintenance of Thumbing Up [J]. Media Observer. 2019 (10). (in Chinese) 